\title{
DOMINICANEANDO. LOS TRES NOMBRES DEL DESPUÉS DE SIEMPRE: ENSAYO TRÍPTICO PARA EL BOSQUEJO DE UNA DOMINICANIDAD INADVERTIDA. EDICIONES LIBRO DOMINICANO, SANTO DOMINGO, 2020, 553 PÁGS. ASIN: B08BX54H2V
}

\author{
Fernando I. Ferrán Brú \\ Profesor-Investigador del Centro de Estudios P. Alemán. Pontificia Universidad Católica Madre y Maestra (PUCMM). \\ República Dominicana. ORCID: 0000-0001-6584-2530, Correo-e: fferran44@gmail.com
}

Cómo citar: Ferrán Brú, F. I. (2021). Dominicaneando. Los tres nombres del después de siempre: Ensayo tríptico para el bosquejo de una dominicanidad inadvertida. Ediciones Libro Dominicano, Santo Domingo, 2020, 553 págs. ASIN: B08BX54H2V. Ciencia y Sociedad, 46(3), 113-118. Doi: https://doi.org/10.22206/cys.2021.v46i3.pp113-118

Ignoro si José Miguel Soto Jiménez leyó El Evangelio de Jesucristo. Se trata de una obra más humana que teológica en la que el autor de esa buena nueva, José Saramago, transcribe una sentencia lapidaria que parece hacerle eco a este exgeneral, laureado poeta, articulista y ensayista dominicano. Escribe el evangelista:

¡Perderás la guerra, no tienes otro remedio, pero ganarás todas las batallas!

Y en efecto, dominicaneando — gerundio del añorado verbo dominicanear, salido de la vivaracha pluma de José Miguel Soto Jiménes- nos lleva a atisbar diversos campos temáticos, pero sin que después de tanto batallar gane y nos libere de la inadvertencia de siempre: la identidad dominicana.

La obra con formato discursivo se centra en la envergadura de todo aquello que identifica a lo dominicano como tal. Para ello, lo mismo rememora

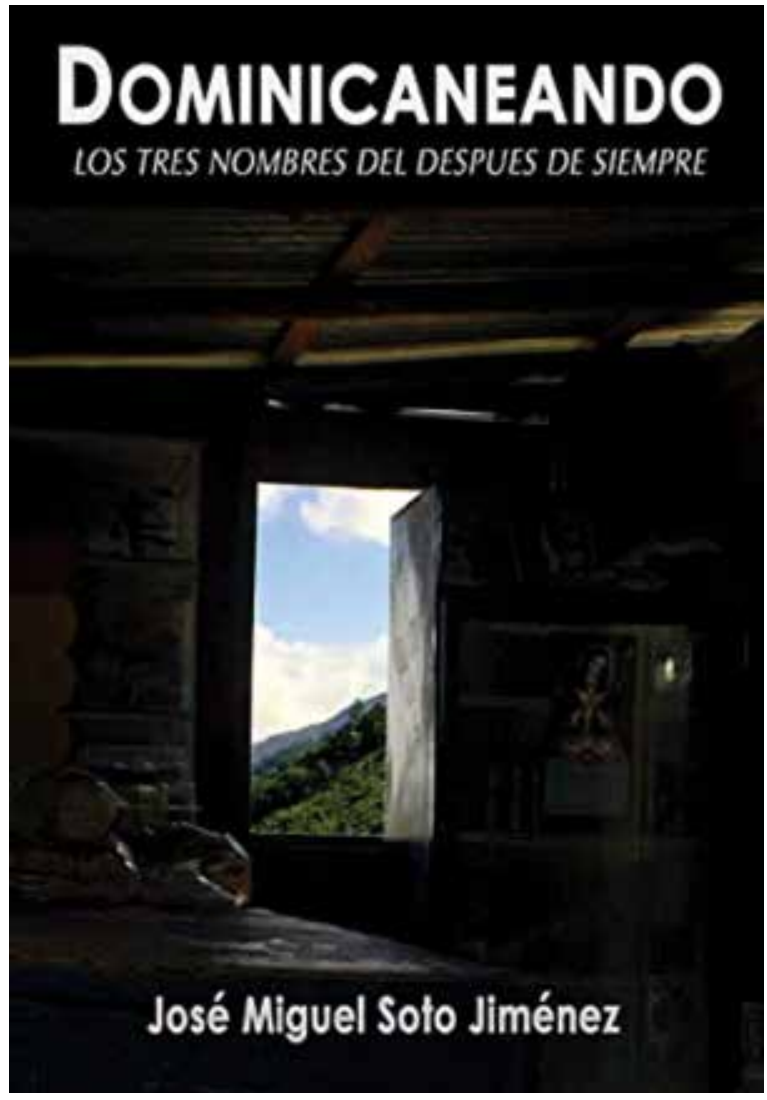


prolijamente y sin referencia ni auxilio bibliográfico personajes históricos (como Cristóbal Colón, Nicolás de Ovando, Santana); evoca eventos de naturaleza histórica (tipo la colonización y la reconquista); adelanta estilos de vida de la población (por ejemplo, el hatero, el tabacalero y otros); describe con maestría costumbrismos rurales (desde el merengue típico, el perico ripiao, pasando por el sancocho de siete carnes y llegando a un rosario inagotable de expresiones religiosas); diagnostica síndromes propios (relacionados al oro, el situado, el pendejo, la vaina y el doble sentido).

Todo esto, hay que reconocerlo, antes de exponer al lector a los acápites frente al espejo de la historia (Soto Jiménez, 2020, p. 479) y su conclusión no concluida (Soto Jiménez, 2020, pp. 521-525).

A lo largo de todo el trayecto del ensayo aquí resenado se percibe que no se trata de un análisis crítico relativo a una exposición teórica o a un propósito vinculado a la bibliografía sobre el tema dominicano, sino más que nada a la curiosidad intelectual e inquietud personal del autor.

Embriagado también por los pormenores narcotizantes de este cuento que emborracha, debo confesar que me he preguntado seriamente si todo este embrollo aquí planteado, no es simplemente la búsqueda de una interpretación sociológica de la dominicanidad y de su historia..., (Soto Jiménez 2020, p. 23; véase también, p. 295).

En cualquier instancia, ninguno de los tres nombres del después de siempre - subtítulo del libro en su carátula frontal — avala afirmar o insinuar que el autor de Dominicaneando responda dicha pregunta. Si algo atestiguan esos nombres es que su embrollo no conduce a alguna pesquisa objetiva — propia de alguna de las diversas disciplinas sociales contemporáneas - $y$, por tanto, tampoco a conclusiones y reflexiones verificables en los hechos.

\section{Su entramado o campo de batalla}

La obra aparece dedicada al pueblo dominicano y su propósito es obvio desde la primera de sus 554 páginas: conocer las causas de las cosas que - de acuerdo al poeta Virgilio- condicionan el estado de ánimo de quienes son felices. Ahora bien, el lector debe asumir como un implícito no tematizado que, a propósito del dominicano y de lo que le atañe, dichas cosas descansan en el anagrama de la dominicanidad (Soto Jiménez, 2020, pp. 13-14), sin que, por tanto, se establezca dicha relación.

En ese contexto, sobresalen dos asuntos decisivos para entender la obra: la intuición del autor y su límite.

a. De un lado, el atisbo popular de Soto Jiménez. Es esto lo que le permite hacer un aporte incuestionable cuando resume en breves líneas aquella dominicanidad en la que se incluye y reconoce.

"Somos ciertamente un sincretismo, una mezcla, una mixtura, una curiosa mescolanza, una ensalada, quizás, un revoltijo insufrible, pero siglo tras siglo, ya somos algo diferente que solo se parece a lo que realmente somos" ( Soto Jiménez, 2020, p. 16).

Otro ejemplo de la capacidad intuitiva del autor es su comprensión general acerca de la población criolla:

Se podría decir que el Pueblo Dominicano se hizo como tal, por el oficio de defenderse en medio de la pobreza, la soledad y el aislamiento, enfrentándonos a las múltiples agresiones de los extranjeros. Ingleses, franceses, haitianos, españoles y gringos varias veces. (Soto Jiménez, 2020, p. 344)

Por otro lado, su perspicacia y lucidez resaltan cuando, por ejemplo, equipara "el síndrome del situado al síndrome de las remesas" y entonces 
subraya "la modorra social ante acontecimientos intolerables" y "ese letargo que practicamos" a tal punto que "en esta situación de desastre controlado, se fue forjando la dominicanidad" (Soto Jiménez, 2020, pp. 309-313).

Igualmente, al cerrar su exposición con ese propósito nos dice:

Nuestra indolencia, desidia de horizontes, es uno de esos trucos que hemos concebido para torear la suerte, y entonces se impone aquí la necesidad de una voluntad política democrática como debe de ser, pero con la autoridad legal y moral suficiente para regular y normar, todas esas aberraciones de nuestro proceder insano. (Soto Jiménez, 2020, p. 479)

b. En otro orden, y a modo de complemento y reflejo de ese atisbo clarividente y acucioso, destacan los límites de la argumentación expuesta por el autor. El principal — aunque no exclusivocuando aporta sus claves de lectura e interpretación de la historia patria.

Una buena ilustración de esto se encuentra cuando el autor - a través de múltiples acontecimientos y capítulos del libro- aborda la vieja alianza entre la iglesia católica y los hateros. Alianza esa que "venía desde la conquista” (Soto Jiménez, 2020, p. 219) y cuya alegada importancia radica en que ambos aspectos asociados "históricamente siempre han actuado mancornados y cuando no lo han hecho, cualquier de esas dos partes no ha tenido éxito en nuestra historia” (Soto Jiménez, 2020, p. 203).

Dado que "el hato fue el verdadero polo de poder económico, social y político en una sociedad que fue fundamentalmente rural" (Soto Jiménez, 2020, p. 244), el remate del proceso pareciera hacerse sentir en pleno siglo xx. Pero la realidad social dominicana es más compleja que el sentido común y cualquier concepción por edificada que sea. En efecto, como si fuera la verdadera síntesis de todo lo acontecido durante el siglo XIX isleño la obra reitera el papel protagónico del hato como modelo societario dominicano. Y lo reitera precisamente antes de dejarlo con todos sus aliados de rodillas, sumisos a los pies de un poder único encarnado en buena parte del siglo xx dominicano en el empresario agroindustrial (azucarero) que fue el dictador Rafael Leonidas Trujillo.

Trujillo, tal como Santana, era ahora el nuevo mesías de la clase hatera, el esperado, el anunciado, el 'hombre necesario', siendo desde sus inicios un importrante terrateniente, criador de ganado y productor de leche, representante como Santana del estamento militar, autoritario y despótico como él. (Soto Jiménez, 2020, p. 376)

A propósito de la deformación analítica para detectar y discernir las consecuencias del proceso de conformación social y cultural dominicana, aunque Soto Jiménez no lo ignora, sí soslaya por completo implicaciones derivadas de hechos históricos como que "el tabaco `fue el gran general restaurador"” (Soto Jiménez, 2020, pp. 243-244).

En ese mismo orden parece confundir trapiches coloniales con el ingenio industrial azucarero e ignorar formalmente que ya a finales del siglo XIX y durante más de la mitad del xx la incidencia de la agroindustria azucarera y sus plantaciones latifundistas se impusieron en el país como principal centro de poder político y económico (Soto Jiménez 2020, pp. 313-324).

La referida reiteración hatera como hilo conductor del acontecer dominicano deja al autor silente ante la conformación sociocultural dominicana en la actualidad, como si el pasado fuera el eterno retorno o el sempiterno presente de la dominicanidad. De ahí, el evidente límite objetivo de sus elocuentes exposiciones destinadas a "dominicanear". La intuición no logra esa acción. 
A la hora de estar dominicaneando hay que reconocer tanto la empresa asumida como el camino correcto que llegue a buen fin. Bien se sabe que no todos los caminos conducen a Roma y - aún menos - cuando se escribe con sentido de urgencia y legítimamente "para cambiar el rumbo pesaroso de la historia" (Soto Jiménez, 2020, p. 521).

\section{Lo inaudito e inadvertido}

El autor sustenta que "nuestros códigos esenciales están ahî", en ese sincretismo que somos (Soto Jiménez, 2020, p. 16). Pero imposible desconocer lo evidente. Todos los pueblos de la historia universal son frutos sincréticos, desde aquel entonces en el que los primeros grupos humanos al pie del Kilimanjaro, o según las últimas evidencias arqueológicas en los suelos de Marruecos, comenzaron a emigrar. Así, pues, ¿cómo discernir nuestros códigos culturales y diferenciarlos de los de tantos otros pueblos?

La respuesta es que, sin el auxilio de un método objetivo de análisis e interpretación, la tarea es y seguirá siendo fallida. En particular, cuando el expositor estudioso carece de un método de estudio probado para inducir los códigos culturales y librar su exposición a la indispensable intersubjetividad de pares que requiere epistemológicamente cualquier disciplina social. He ahí —en esa carencia de métodoel talón de ese gran guerrero émulo de Aquiles cuando se dispuso a batallar dominicaneando.

Cada una de sus afirmaciones, por atinadas y correctas que sean, permanecen siendo de manera objetiva inverificables, pues no están avaladas ni teórica ni metodológicamente por un procedimiento objetivo e imparcial al alcance de cualquier lector o investigador menos apasionado e instintivo.

Desprovisto de método, el libro desmedra su valor mientras hilvana en una ingeniosa y locuaz narración el decir básico del dominicano, en el que desconoce qué hace, piensa, quiere, olvida, detesta, ama, aprecia, valora e incluso recuerda, desea, padece, añora, extraña y silencia.

“'Somos lo que hablamos' y nuestra llave maestra está en lo que decimos cotidianamente, eso es lo que nos descifra, lo que nos descodifica", (Soto Jiménez, 2020, p. 20).

Merece reiterar esa limitativa comprensión gnoseológica somos lo que hablamos, y no nuestros impulsos, pulsiones, acciones, necesidades, bondades, verdades y mentiras, engaños, organizaciones, convivencias, culpas y perdones. Es como si el verbo pudiera ser divino, sin origen ni acciones ni condiciones conducentes a un fin.

Sin método en su haber, el relator de Dominicaneando se explaya copiosamente en un largo rosario de refranes y dichos populares dominicanos y dicho sea de paso no pocas veces- de allende, para finalmente articular situaciones de la vida diaria de la población dominicana y de su historia porque somos lo que hablamos. No por este proceder deja de salir airoso en cada una de las siete partes o capítulos de la obra, que como medallas penden del pecho del victorioso general. Triunfa la pasión con que aborda y articula eventos y situaciones a la luz de una irrepetible sarta de expresiones, algunas de ocasión y otras sabias y profundas, interpretando todo a modo de letanía al ritmo de Jesús, María y José, bajo el manto devocional de la Madre del Verbo, Tatica.

Sin embargo, y a pesar de variados logros parciales, el autor no logra disipar ni rematar las dudas que surgen en el campo de batalla académico a propósito de una obra ideada sin teoría ni metodología y aún menos orden metodológico. Es por eso lo fallido de su intento al momento de tematizar tanto afán.

Lo que intentamos proponer tiene nombre $y$ se llama paremiología, del griego paronimia, proverbio, y logos, que significa tratado. La ciencia que estudia los refranes, aforismos, 
dichos sentenciosos y otros enunciados, tales como: tremenda vaina, se fuñó Bayajá, se jodió Villa. 'Dejémonos de caballadas', y ‘acabemos de una vez por todas con esta pendejada'. (Soto Jiménez, 2020, p. 21)

Sus autores de referencia son Juan Bosch, Pedro F. Bonó, Américo Lugo, Harry Hoetnik y Summer Welles (Soto Jiménez, 2020, p. 23) y no solo Juan Isido Núñez, Pedro Henríquez Ureña, Rodríguez Demorizi, Juan Antonio Alix, Ramón Emilio Jiménez y Miguel Ángel Jiménez (Soto Jiménez, 2020, p. 21).

Dominicaneando se diferencia en primera y última instancia por eso que es tan típicamente dominicano: la informalidad, esta vez metodológica. La locuacidad, el costumbrismo y la improvisación podrán ser imprescindibles a la hora de descollar, pero son insuficientes para descubrir y decodificar la dominicanidad en el tiempo y poder evitar que quede cautiva y sin devenir en un pasado sin porvenir. Esa es la razón por la que la sempiterna semejanza dominicana en sí misma es infecunda, pues yace retenida en el impotente ejercicio liberador de dominicanear de la mano de la paremiología:

Ser dominicano es una forma irrenunciable de arrastrar cual penitencia, lo que hemos sido siempre, y por donde quiera que vamos nos portamos tal cual, porque, aunque queramos actuar de otra forma, seguimos siendo lo que somos. No es solo la manera de hablar, gesticular, caminar, movernos de un lado para el otro, hasta jartarnos de impaciencia y ansiedad. Es nuestro propio accionar en todas las circunstancias. (Soto Jiménez, 2020, p. 503)

Pareciera insinuarle al lector que el dominicano se asemeja al mítico Sísifo. Este, empujando el peso de su falta, independientemente de lo que alegue o haga, se repite y no deja de padecer su destino, sin por ello cambiar ni mutar, siempre igual a sí mismo y sin sentido, eterno deudor de su pasado sin finalidad ni fin.

Nada tan escurridizo como el espejismo de la realidad dominicana. Tan ilusa e irreal como esta tautología conclusiva a la que llega quienquiera sale al combate desprovisto de armas metodológicas y planes teóricos que le permitan inducir, de capítulo en capítulo, disputándole a uno y otro tema, la victoria final:

"Somos lo que somos y no otra cosa. Somos lo que hemos sido, y seremos eso hasta que se gaste la eternidad como una vela vieja" (Soto Jiménez, 2020, p. 524).

A pesar de esa afirmación repetitiva e infecunda hay que observar que con este libro se tributa al pueblo dominicano una obra importante que hay que leer, aun cuando sea para reconocer que, después de siempre, la dominicanidad aún permanece inaudita e inadvertida.

\section{Una conclusión inconclusa}

A la luz de lo que precede, pido excusas por la alusión al canto de Juan Luis Guerra y concluyo que somos más, mucho más, que solamente un indefinido agujero sincrético en medio del mar y el cielo, o bien, como escribe el autor, la isla [que] huele a desastre (Soto Jiménez, 2020, p. 191).

Así como Moisés no entró en la tierra prometida - a pesar de haberla atisbado a lo lejos desde el desierto- algo análogo acontece con José Miguel Soto Jiménez respecto a lo dominicano. Sin poder desentrañarlo y explicitarlo, solamente intuyó desde lejos lo que es dicho de "la Patria, esa abstracción de nuestro destino" (2020, p. 524) que hay que defender "palmo a palmo...con los puños, con el corazón y con las armas, pero al mismo tiempo... mentalmente" (Soto Jiménez, 2020, pp. 14-15). 
Quizás por esa misma abstracción patria deja a sus lectores la inconclusa tarea moral e intelectual de por fin adentrarse en el susodicho anagrama de la dominicanidad; o bien, en el código o ADN cultural (Ferrán, 2019, pp. 268 y 477) que está presente y muta no solo en lo que decimos, sino también en el modo de actuar, organizar, valorar y querer del pueblo dominicano, pues del dicho al hecho hay mucho trecho.

\section{Referencias}

Ferrán, F. (2019). Los herederos. ADN cultural del dominicano. Colección Cultural del Banco Central de la República Dominicana.

Soto Jiménez, J. (2020). DOMINICANEANDO. Los tres nombres del después de siempre: Ensayo triptico para el bosquejo de una dominicanidad inadvertida. Impresora Soto. 